\title{
CORRIGENDUM
}

\section{Hypertension in Mexico and among Mexican Americans: prevalence and treatment patterns}

\author{
S Barquera, RA Durazo-Arvizu, A Luke, G Cao and RS Cooper \\ Journal of Human Hypertension (2008) 22, 652; doi:10.1038/jhh.2008.49
}

Correction to: Journal of Human Hypertension; advance online publication, 28 February 2008; doi:10.1038/jhh.2008.9

Since the publication of the above article, the authors have noticed that Figure 3 is incorrect.

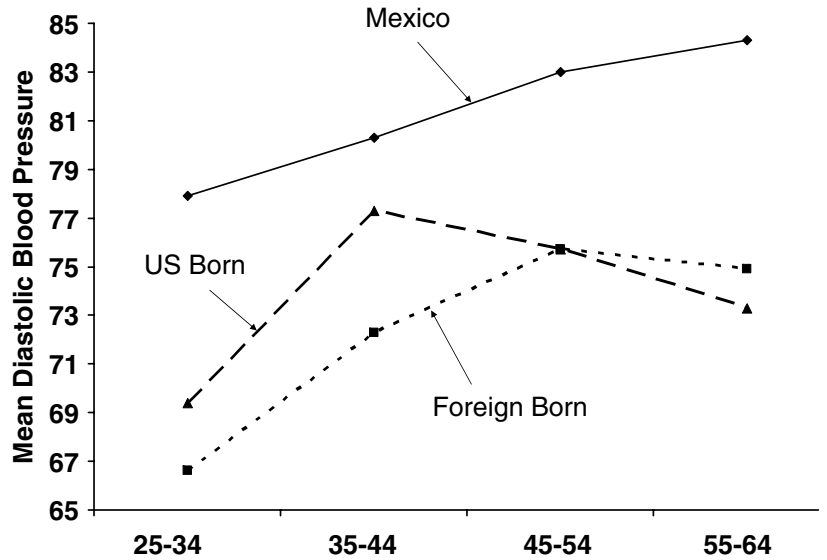

Figure 3 Sex-adjusted mean diastolic blood pressure (DBP) by decade of age for residents of Mexico selected by ENSA 2000 (Encuesta Nacional de Salud 2000), US-born and foreign-born Mexican Americans (MAs) participating in NHANES 1999-2004 (National Health and Nutrition Examination Survey).
The correct Figure 3 is shown below.

The authors would like to apologize for this mistake. 